\title{
Da Invisibilidade ao Reconhecimento: mulheres rurais, trabalho produtivo, doméstico e de care
}

Karolyna Marin Herrera'

\section{Resumo}

Este artigo pretende problematizar a situação de invisibilidade e falta de reconhecimento das mulheres no meio rural da região Sul do Brasil, por meio da reflexão das possibilidades de superação de sua condição. Para tanto, foi proposta a adoção da perspectiva analítica da multifuncionalidade agrícola para análise das atividades exercidas pelas mulheres rurais, uma vez que esta perspectiva almeja ir além das abordagens de orientação meramente produtivista e pretende evidenciar as funções não produtivas da agricultura. Na pesquisa empírica, foram identificadas as diversas e diferentes atividades que compõem os trabalhos produtivo, doméstico e de care de um grupo de 18 agricultoras integrantes do Movimento de Mulheres Camponesas (MMC) residentes no município de Quilombo, no oeste de Santa Catarina, na região Sul do Brasil. Verificou-se que as agricultoras têm papel fundamental no que concerne à manutenção e reprodução social da agricultura familiar, uma vez que as suas atividades cotidianas estão relacionadas integralmente às suas famílias e a seus estabelecimentos agrícolas. Nessa perspectiva, a lente da multifuncionalidade funciona como uma poderosa ferramenta que possibilita visibilizar o papel da mulher no campo.

Palavras-chave: Mulheres rurais. Multifuncionalidade Agrícola. Gênero. Sociologia Rural.

\section{Introdução}

A situaçáo de desigualdade de gênero no meio rural está relacionada com a naturalização do papel do homem e da mulher, que está vinculada à relação hierárquica dentro das famílias rurais, cuja base material se ancora na divisão sexual do trabalho. Essa diferenciação é condicionada socialmente através de vivências, símbolos e representaçóes, e se reproduz no cotidiano da dinâmica familiar. Segundo Sorj (2010), as desigualdades e diferenças de gênero ${ }^{2}$ repousam sobre uma norma social que associa o feminino à domesticidade e que

\footnotetext{
I Doutoranda do Programa de pós-graduação em Sociologia Política da Universidade Federal de Santa Catarina (UFSC).E-mail: karolynaherrera@yahoo.com.br.

2 A concepção de gênero adotada neste artigo se baseia no clássico texto de Scott (1995).
} 
expressa na divisão sexual do trabalho, atribuindo prioritariamente às mulheres a responsabilidade do trabalho doméstico e com os cuidados da família.

Devido à divisão sexual das atividades, usualmente cabe ao homem a responsabilidade do trabalho produtivo da agricultura, e à mulher ${ }^{3}$, o trabalho relativo aos cuidados domésticos e de caré . A divisão sexual do trabalho está, também, relacionada com a representação social do ser mulher e do ser homem na nossa sociedade, ou seja, em última instância, o valor social do trabalho é dado a partir de quem o executa e náo pela natureza do trabalho em si (HIRATA; KERGOAT, 2007).

A denominação de trabalho "pesado" e "leve", abordados por Paulilo (1987), corrobora essa afirmativa, uma vez que tal diferenciação é imprecisa e possui determinantes culturais, pois o que é considerado "leve" ou "pesado" depende da perspectiva social analisada. Dentro das atividades cotidianas, homens e mulheres realizam trabalhos pesados, tais como cortar lenha, lidar com a roça, carregar filhos pequenos e transportar água quando esta está localizada distante do domicílio. No entanto, o que se pode constatar, conforme (PAULILO, 1987), é que, quanto mais proeminente o trabalho executado, mais a mulher encontra-se excluída dele. Ou seja, "[...] o trabalho é leve (e a remuneração é baixa), não por suas próprias características, mas pela posição que seus realizadores ocupam na hierarquia familiar" (PAULILO, 1987).

No entanto, diversos estudos apontam (NEVES; MEDEIROS, 2013) que as atividades das mulheres rurais não estão apenas circunscritas aos trabalhos doméstico e de care, pois elas também realizam atividades nas lavouras e na produção de alimentos, que muitas vezes não são reconhecidas como parte

3 Cabe ressaltar que esta afirmação é condizente com o contexto analisado, qual seja, a realidade de mulheres em áreas rurais do Sul do Brasil. E essa realidade pode ser diferente em comunidades indígenas elou não ocidentalizadas. Por exemplo, no caso latino-americano estudado por Weinstock (2014), a autora ressalta que [...] en las culturas originarias podemos reconocer estructuras de diferencia semejantes a lo que llamamos relaciones de género en la modernidad, con jerarquías claras de prestigio entre la masculinidad y la feminidad, representados por figuras que pueden ser entendidas como hombres y mujeres. Pero si bien el género existe. lo hace de una forma diferente que en la modernidad". Um estudo emblemático sobre esta temática é o da antropóloga americana Margareth Mead, Sexo e temperamento em três sociedades primitivas (1935). Mead foi pioneira ao propor que as caracteristicas masculinas e femininas refletiam as influências culturais e sociais, não se limitando às diferenças biológicas.

4 Segundo Hirata (2010, p.43), "[...] o termo care é dificilmente traduzível, porque polissêmico. Cuidado, solicitude, preocupação com o outro, estar atento a suas necessidades, todos esses diferentes significados estão presentes na definição do care". 
produtiva da agricultura. Dentro desse contexto, podemos afirmar que a realidade das mulheres no âmbito rural brasileiro é marcada por muito trabalho e pouco reconhecimento. As agricultoras, apesar de se dedicarem integralmente às atividades produtivas e reprodutivas, ou seja, aos trabalhos doméstico e de care, em seu cotidiano sofrem ainda hoje de invisibilidade social e de falta de reconhecimento como trabalhadoras e cidadâs (NEVES; MEDEIROS, 2013; FARIA, 2009).

Geralmente o trabalho realizado pelas agricultoras no âmbito produtivo é visto como "ajuda" ao marido ou à família, mesmo quando cada agricultora trabalha tanto quanto seu marido ou executam as mesmas atividades que eles. As atividades agrícolas exercidas por elas são vistas como uma extensão intrínseca às suas atribuiçóes de mãe e esposa e, muitas vezes, recebem pouca ou mesmo nenhuma remuneração pelas atividades executadas por elas (BRUMER, 2004). Por sua vez, as atividades realizadas na esfera privada, de cunho reprodutivo (trabalhos doméstico e de care), são, geralmente, reconhecidas pela sociedade como atividades naturais do ser mulher, ligadas ao afeto e ao carinho que a ela destina à sua família, e, por este motivo, têm a sua importância obscurecida (BORIS, 2014).

Uma análise do trabalho da mulher no meio rural através de perspectivas que evidenciam a visão produtivista da agricultura familiar ${ }^{5}$ impossibilita a visibilidade de seu trabalho. Primeiro, porque o reconhecimento do papel desempenhado pelas mulheres nos trabalhos doméstico e de care já são, por si mesmo, um velho entrave, haja vista a dificuldade enfrentada pelas feministas em evidenciar a importância econômica dos trabalhos doméstico e de care. Segundo, quando os estudos a respeito dos trabalhos doméstico e de care recaem sobre o espaço rural, as análises tornam-se ainda mais intrincadas, porque, segundo Paulilo (2013), "[...] as [próprias] mulheres veem os campos em volta de sua moradia como uma extensão da casa e não separam o trabalho que fazem nos dois espaços, declarando todas as atividades [que realizam] como trabalho doméstico".

5 No Brasil, a expressão "agricultura familiar" ganhou projeção nacional no final dos anos 1980 e, principalmente, a partir da primeira metade da década de 1990. O debate, inicialmente, concentrou-se no campo político e, posteriormente, acadêmico. Wanderley (2003b) propõe que o(a) agricultor (a) familiar representa o camponês ou a camponesa tradicional que se adaptou às transformações em curso na agricultura, tornando-se um(a) agricultor(a) moderno(a). Porém este(a) agricultor(a) familiar, apesar de moderno(a), não perde suas raizes históricas firmadas no contexto da tradição camponesa. Segundo a autora, existem rupturas e continuidades que forjam a identidade dos/das agricultores/as familiares. 
As mulheres exercem um papel fundamental como agentes nas estratégias de manutenção e reprodução da agricultura familiar, apesar de sua situação de desigualdade frente aos homens. As atividades realizadas pelas agricultoras em seus cotidianos são essenciais para a subsistência biológica e socioeconômica das famílias, para o bem-estar, para a segurança alimentar e a preservação do meio ambiente.

No que se refere às tarefas domésticas e de care, elas são centrais para a manutenção da força de trabalho, para o cuidado e desenvolvimento das crianças, doentes, deficientes físicos e mentais, e pessoas mais velhas, além de serem essenciais para a subsistência biológica e o bem-estar das famílias (BORDERÍAS; CARRASCO; TORNS, 2011). Por sua vez, nas atividades produtivas, as mulheres do campo realizam funçóes em todos os âmbitos de trabalho (agrícolas e não agrícolas) necessários para a reprodução socioeconômica e o bem-estar de suas famílias.

Dada a relevância da contribuição da mulher para a reprodução social de suas famílias e da própria agricultura familiar no Brasil, é imperativo compreender detalhadamente as atividades exercidas por ela através de uma lente analítica que evidencie o seu papel como trabalhadora rural tanto no aspecto produtivo como no náo produtivo da agricultura, permitindo, desta forma, que o trabalho exercido pelas mulheres rurais se torne visível à sociedade em sua integridade.

Consonante com a necessidade de evidenciar os aspectos náo produtivos da agricultura, abordagens contemporâneas da sociologia rural (WANDERLEY, 2003a; CAZELLA; BONNAL; MALUF, 2009; CARNEIRO; MALUF, 2003) propóem o conceito de multifuncionalidade agrícola, que pretende compreender e analisar os fenômenos particulares da agricultura familiar a partir de uma perspectiva multidimensional, para além do aspecto produtivista da agricultura. Tais aspectos abrangem as dimensóes: social, econômica, cultural e ambiental.

Com objetivo de contribuir para este debate, neste artigo, apresento uma análise das atividades cotidianas de 18 agricultoras ${ }^{6}$ integrantes do Movimento

6 Foram realizadas 18 entrevistas semiestruturadas com duração de aproximadamente 1,5 horas cada e tiveram lugar na casa das entrevistadas. As entrevistas ocorreram no periodo de julho a agosto de 2014. Nesta pesquisa, foram realizadas, adicionalmente, observações não participantes com anotações em diários de campo, bem como, foram consultados documentos de dados secundários. 
de Mulheres Camponesas (MMC) e residentes no município de Quilombo, na região oeste do estado de Santa Catarina.

O MMC surgiu em 1983 com o nome de Movimento de Mulheres Agricultoras (MMA). A formação inicial do MMA foi composta por trabalhadoras rurais catarinenses em meio a um cenário desfavorável ao desenvolvimento e manutenção da agricultura familiar na região oeste de Santa Catarina. A organização inicial do movimento recebeu a influência marcante da Igreja Católica, que no contexto da década de 1980 estava engajada em projetos de transformação social através das chamadas Comunidades Eclesiais de Base (CEBs), inspiradas nos ideários da Teologia da Libertação.

A partir da década de 1990, o MMA aproxima-se de outros movimentos sociais rurais organizados por mulheres, conforme aponta Boni (2012). Assim, une-se a organização criada em 1995, a Articulação Nacional de Mulheres Trabalhadoras Rurais (ANMTR), que tinha por objetivo reunir as mulheres dos Movimentos Autônomos, da Comissão Pastoral da Terra (CPT), do Movimento dos Trabalhadores Rurais Sem Terra (MST), da Pastoral da Juventude Rural (PJR), do Movimento dos Atingidos pelas Barragens (MAB), de sindicatos de Trabalhadores Rurais e, no último período, do Movimento dos Pequenos Agricultores (MPA).

A partir de então, o movimento segue em estreita colaboração com a ANMTR. Depois de várias atividades nos grupos de base, nos municípios e estados, o MMA procurou ultrapassar as fronteiras estaduais, promovendo, assim, a realização de seu primeiro congresso nacional em 2003, com a participação de vários movimentos autônomos de mulheres existentes no Brasil. Em 2004, o movimento é renomeado como Movimento das Mulheres Camponesas (MMC). A mudança do nome está vinculada à necessidade de afirmar a identidade camponesa, que, segundo as integrantes do movimento, permite englobar as diferentes identidades de trabalhadoras no meio rural.

A partir da articulação com a Via Campesina e outros movimentos sociais, o MMC sente a necessidade de se reunir a esses movimentos. Desta forma, no ano de 2013, o MMC promoveu o I Encontro Nacional em Brasília. Desde então, a organização do movimento se efetivapor meio de grupos de base, diretorias e coordenaçóes municipais, regionais, estaduais e nacional.

A escolha por investigar integrantes desse movimento se justifica na hipótese de que o MMC, por meio de seu discurso e prática, contribui para a 
consciência das mulheres de sua condição de agricultora. Ademais, acredito que a reivindicação por parte desse movimento pela produçáo de alimentos saudáveis via construção de um projeto agroecológico de agricultura, bem como pelo esforço por evidenciar a importância da mulher nas atividades agropecuárias, influencia positivamente na prática dessas agricultoras e colabora para a visibilidade das contribuiçôes sociais, culturais e ambientais da agricultura.

Com relação ao município ${ }^{7}$ escolhido para esta pesquisa, Quilombo, a escolha se deu pelas suas características socioeconômicas. Apresentando características muito semelhantes às da maioria dos pequenos municípios da região oeste de Santa Catarina, o município possui cerca de 10 mil habitantes e apresenta uma estrutura fundiária baseada em pequenas propriedades agrícolas, sustentadas pelo trabalho familiar. As atividades agrícolas correspondem a $48 \%$ do movimento econômico do município. Adicionalmente, neste município é possível encontrar um número significativo de integrantes do MMC.

Com o intuito de evidenciar o papel da mulher rural na manutençáo e reprodução social da agricultura familiar, partindo da análise das atividades cotidianas das 18 entrevistadas, neste artigo procuro realizar aproximaçóes entre a sociologia rural e a sociologia das relaçóes de gênero com enfoque na área do trabalho. Minha intenção é auxiliar no processo de visibilizaçáo das atividades não produtivas das mulheres rurais, materializadas nos trabalhos doméstico e de care, através de uma perspectiva que valorize os aspectos sociais, econômicos, culturais e ambientais da agricultura, a multifuncionalidade agrícola.

Esta discussáo se faz pertinente, pois, sendo o feminismo brasileiro muito marcado por um viés urbano ${ }^{8}$, inclusive no que diz respeito aos estudos dos trabalhos doméstico e de care, o estudo das relaçóes e desigualdades de gênero no meio rural se mostra relevante tendo em vista "desurbanizar" as pautas e direcionar a discussão dos temas relacionados à ruralidade e às mulheres, tais como, a relevância do trabalho não produtivo para a agricultura, a soberania alimentar, a preocupação da distribuição da terra, dentre outras questóes.

7 Para a realização das entrevistas, visitei oito comunidades desse município, são elas: Santa Lúcia, São João, Salto da Saudade, São Ricardo, Vila Gaúcha, Fortaleza, Manuel Mayer e São José.

8 Os estudos feministas na América Latina nas últimas décadas têm se voltado em grande medida para questões relacionadas à identidade e reconhecimento de mulheres urbanas, especialmente no que diz respeito aos direitos reprodutivos e à violência contra a mulher, deixando em segundo plano questões diretamente relacionadas às mulheres do campo, tais como, os problemas relativos aos direitos de propriedade, trabalho e distribuição de renda, conforme Deere e León (2002). 


\section{A multifuncionalidade agrícola}

A noção de multifuncionalidade agrícola está inserida dentro da perspectiva da nova ruralidade, que delimita sua unidade de análise em funçáo do conceito de território rural e o associa a três dimensóes fundamentais: a proximidade com a natureza; a ligação com as cidades; e as relaçóes interpessoais derivadas da baixa densidade populacional e do tamanho reduzido de suas populaçóes (WANDERLEY, 2000; MURDOCH, 2006; ABRAMOVAY, 2009).

Não se resumindo ao lugar onde se produz os alimentos, o território rural é visto como um espaço de preservação ambiental, de manutençáo do patrimônio cultural, promotor de soberania alimentar, ou seja, um lugar de reprodução social. A nova ruralidade não limita suas análises aos aspectos produtivos e econômicos da agricultura, mas, pelo contrário, enfatiza a reconstrução dos significados do território e da própria agricultura.

Neste sentido, esta nova abordagem procura ressignificar o conceito de ruralidade para além das atividades produtivas, sem abandonar as premissas e condicionantes para que ela possa ocorrer, tais como: o acesso aos meios de produção e, em especial, à terra; a ampliação dos níveis de renda dos agricultores por meio do acesso às políticas públicas e ao mercado; a agregação de valor, expressa na qualidade dos produtos; a manutenção do tecido social; e a conservaçáo dos recursos naturais e das paisagens, entre outros aspectos.

Neste contexto, a noção de multifuncionalidade da agricultura familiar representa uma tentativa de reconhecer que os estabelecimentos agrícolas e, portanto, os agricultores e agricultoras que neles vivem e trabalham, estabelecem suas estratégias de manutenção e reprodução social desempenhando outras funçóes que não exclusivamente produtivas e mercantis. Nesta perspectiva, esta noção procura romper com o enfoque economicista da agricultura.

O debate em torno da multifuncionalidade da agricultura foi introduzido na agenda internacional na Conferência das Naçóes Unidas sobre Meio Ambiente e Desenvolvimento, Eco 92. Para Moruzzi Marques e Flexor (2007 apud GAVIOLI; COSTA, 2011), a multifuncionalidade é concebida de duas maneiras no campo político e acadêmico. Primeiramente, a multifuncionalidade agrícola é reconhecida como um conjunto de ideias capaz de reorientar as políticas agrícolas e a agricultura em direção a outro modelo de desenvolvimento. Por outro lado, esta noção é vista como um referencial analítico que busca redefinir as externalidades associadas à prática agrícola. 
Dentro deste contexto, o reconhecimento da noçáo de multifuncionalidade da agricultura pelas políticas públicas de países da União Europeia, em especial a França, foi objeto de vários estudos e pesquisas ${ }^{9}$. Por sua vez, o tema da multifuncionalidade, impulsionada pelas políticas públicas, provocou um questionamento da renovaçáo dos enfoques da ruralidade, dos conceitos e das agendas de investigação nos centros de pesquisa (SABOURIN, 2005). Ainda segundo Sabourin (2005), esse interesse náo esteve presente apenas no contexto europeu, a noção de multifuncionalidade despertou novas investigações realizadas na Europa por autores como Huylebroeck et al. (2007), e na América Latina pelos autores Cazella, Bonnal e Maluf (2009); Carneiro e Maluf (2003), entre outros.

Ao promover o rompimento com a visão hegemônica da função econômica da agricultura, o enfoque multifuncional permite que o olhar seja lançado sobre os sujeitos rurais, sobre o território onde eles estáo situados, para a sociedade e também para as políticas públicas do campo. Neste sentido, “[...] mais que focalizar a atividade agrícola, entendida pura e simplesmente como um setor econômico, o que se privilegia é a própria família de agricultores, em suas complexas relaçóes com a natureza e a sociedade que moldam as formas particulares de produção e de vida social" (WANDERLEY, 2003a, p. 9).

Levando em consideração o modo de vida das famílias rurais, a noção de multifuncionalidade agrícola está associada a quatro funçóes do exercício da atividade agrícola, definidas por Cazella, Bonnal e Maluf (2009):

a) Reproduçáo socioeconômica das famílias: aborda a fonte de recursos para os membros das famílias rurais (geração de trabalho e renda), as práticas de sociabilidade, a condição de permanência no campo, as condiçóes de instalação dos jovens e as questóes relativas à sucessão do responsável pela unidade produtiva. Dentro dessa função, torna-se central a análise da pluriatividade da atividade agrícola e das atividades não reconhecidas em torno do conceito de trabalho produtivo, tais como as atividades domésticas e de care.

b) Promoção da segurança alimentar da sociedade e das próprias famílias rurais: abrange a produção para autoconsumo das famílias e a

9 Para Sabourin (2005), a politica de multifuncionalidade na Europa caracteriza-se pela remuneração dos agricultores pelos bens públicos ou amenidades associadas à sua atividade produtiva. 
produção mercantil dos alimentos, considerando, também, o acesso aos alimentos por parte das famílias e da sociedade e a qualidade dos mesmos. Esta função multifuncional também leva em consideração as opçóes técnico-produtivas dos agricultores e os canais principais de comercialização da produção.

c) Manutenção do tecido social e cultural: além da importância da reprodução socioeconômica já citada anteriormente, esta função refere-se à preservação e ao melhoramento das condiçóes de vida das comunidades rurais, levando em conta os processos de elaboração e legitimação de identidades sociais e de promoção da sociabilidade das famílias e das comunidades rurais.

d) Preservação dos recursos naturais e da paisagem rural: essa dimensão tem como referência o uso sustentável dos recursos naturais por parte da agricultura familiar, as relaçóes entre as atividades econômicas e a paisagem, e a preservação da biodiversidade.

Sendo assim, "a noção de multifuncionalidade da agricultura teria que ser capaz de unificar as diferentes demandas e preocupaçóes em relação ao mundo rural e às unidades familiares que o compóem, numa espécie de nova síntese em substituição ao paradigma que esteve na base da 'modernização da agricultura" (CARNEIRO; MALUF, 2003, p.21).

O reconhecimento da agricultura familiar desde uma perspectiva integradora permite que emerja a consciência da sociedade (e das próprias famílias rurais) sobre a importância do papel da agricultura familiar. Contudo, para que seja possível evidenciar o papel das agricultoras por meio dessa perspectiva analítica, faz-se necessário levar em conta as dinâmicas internas da unidade familiar para que seja possível apreender sua participação na formulação de estratégias reprodutivas e na articulação com os condicionantes externos e internos. Essas dinâmicas estão associadas ao bem-estar das famílias, à educação dos filhos, à produçáo de alimentos para o autoconsumo, à sociabilidade para o trabalho e o lazer, ao cuidado com a terra etc.

\section{Reprodução Socioeconômica}

A compreensão do meio rural, segundo Wanderley (2009), decorre da percepção deste espaço como suporte de relações sociais específicas, ou seja, 
como um espaço de vida singular, cujas relaçóes não só dependem da dinâmica social interna, mas também das formas de inserção da vida social externa a este meio. A dinâmica interna se caracteriza por relaçóes sociais fundadas em laços de parentesco e de vizinhança, e a "vida social externa" é constituída por meio da integração com os espaços sociais mais amplos, sobretudo nas complexas relaçóes com o mercado e com a vida urbana. Assim, a vida social dos habitantes do campo é o resultado do entrelaçamento das relaçóes sociais que atravessam o espaço rural.

Dentro desse contexto, as análises da reprodução social dos habitantes do meio rural estão vinculadas às condiçôes de existência social desses agentes. Isto porque a agricultura familiar enquanto atividade social apresenta uma estreita relaçáa entre posiçáo social, profissional e familiar dos agricultores e agricultoras (BRUMER; DOS ANJOS, 2008). Ou seja, conforme menciona Bourdieu (2002), as estratégias de reprodução social adotadas pelas famílias rurais passam pela posição que elas ocupam no espaço social, a partir de uma socializaçáo que engendra determinadas disposiçôes, influenciadas pelas relaçóes com a vida social externa ao espaço rural, mas não sendo ditadas por essas regras externas.

As estratégias de reprodução social da agricultura familiar, portanto, constituem um sistema e compreendem o conjunto das práticas pelas quais cada membro da família ou a família rural como um todo tende, consciente ou inconscientemente, a manter ou a melhorar sua posição na estrutura social. Essas estratégias não têm por princípio uma intenção consciente e racional, mas sim são as disposiçóes do habitus ${ }^{10}$ que tendem espontaneamente a reproduzir as condiçôes de sua própria produção.

No que concerne aos agricultores familiares, eles geralmente consideram nas suas estratégias de reprodução as questóes relativas ao bem-estar de sua família (e, em certa medida, de sua comunidade), as questóes relativas à sucessão da propriedade e herança familiar, as condiçóes de permanência no campo, as práticas de sociabilidade e as estratégias relacionadas às fontes de recursos para os membros das famílias (atividades econômicas realizadas na

10 Para Bourdieu (1996), o habitus é um sistema aberto de disposições, ações e percepções que os sujeitos adquirem com o tempo em suas experiências sociais, tanto na dimensão material, corpórea, quanto simbólica, cultural, entre outras. 
propriedade familiar e as possibilidades de emprego e de obtenção de renda fora da propriedade rural).

O interesse em analisar as estratégias de reprodução social da agricultura familiar decorre, por um lado, dos elevados índices migratórios do meio rural em direção às cidades, com destaque para os jovens e mulheres, o que implica no crescente processo de envelhecimento da população e masculinização do campo. Por outro lado, pelo aumento dos problemas ligados à sucessáo geracional nos estabelecimentos familiares, que acabam por colocar em risco a manutenção e reprodução social da agricultura familiar enquanto categoria social. E, principalmente, pela falta de reconhecimento do trabalho desempenhado pelas mulheres rurais no âmbito da agricultura familiar.

\section{Trabalhos doméstico e de care}

Os trabalhos doméstico e de care consistem em uma estratégia de reprodução social que estão voltadas para a reprodução biológica, de bem-estar e de manutenção das famílias urbanas e rurais. Realizado quase que exclusivamente por mulheres, os trabalhos doméstico e de care foram historicamente invisibilizados" em nossa sociedade e, por este motivo, as tarefas voltadas a esse fim não são reconhecidas como estratégias centrais para a manutenção e reprodução social.

O conceito de care possui uma característica comum a outros conceitos, como os de "trabalho" e "gênero", no que se refere à sua ação multidimensional e transversal. O care refere-se ao componente do trabalho reprodutivo que não equivale ao trabalho doméstico, mas que usualmente é realizado em conjunto com as atividades domésticas, "[...] o trabalho de care envolve serviços pessoais para outrem: são atividades que se voltam para as necessidades físicas, intelectuais e afetivas e para outras demandas emocionais de cônjuges, filhos e pessoas idosas, doentes ou com deficiências" (BORIS, 2014).

Esse conceito foi cunhado por Carol Gilligan em 1982. Essa autora discutiu, em sua obra "Uma Voz Diferente", a existência de uma moral distinta entre meninos e meninas, relacionando o trabalho de cuidado, ou a ética

II Segundo Gelinski e Pereira (2005), as teorias econômicas convencionais e as estatísticas nacionais, utilizadas para definir as políticas macroeconômicas, não consideram e nem contabilizam o universo do trabalho doméstico e de care devido ao fato de que estes não estão orientados para o mercado. 
de care, com uma responsabilidade moral inerente às meninas. Contudo, Gilligan não avançou na discussão da construção social da ética de care. Quem o fez, pioneiramente, foi Joan Tronto (1993). Tronto revelou que homens e mulheres podem exercer atividades de care; porém, como essas atividades têm sido atribuídas socialmente às mulheres ao longo da história, elas são consideradas, predominantemente, como femininas. Segundo Guimarães, Hirata e Sugita (2011), o care remete à questão de gênero, na medida em que essa atividade está profundamente naturalizada, como se fosse inerente à posição e à disposição femininas (babitus).

A literatura sobre o care busca refletir sobre a responsabilidade da mulher pelo cuidado não remunerado para com a sua família, equacionando a relação entre o trabalho doméstico e a opressão das mulheres (BORIS, 2014).

Segundo a bibliografia especializada, o care está presente em todas as atividades cotidianas, quer seja atividades de manutenção da casa, da existência pessoal e do carinho e afeto para com outra pessoa. Esse trabalho requer, segundo Tronto (1993): carin gabout (preocupar-se com), que implica o reconhecimento de uma necessidade e a conveniência em atendê-la; supóe uma capacidade ética de atençáo, taking care of (ocupar-se de, cuidar de), que se refere à responsabilidade (moral) de atender à necessidade identificada, care-giving (dispensar cuidados), que compreende a prática do cuidado, implica a mobilização de uma competência, care-receiving (receber cuidados), que remete à reação de quem recebe o cuidado, ou seja, aquele que recebe os cuidados é o único que pode dizer se eles foram eficazes e pertinentes. Esta última situação supóe outra qualidade moral essencial: a responsiveness ('receptividade").

Os trabalhos doméstico e de care são realizados para o cuidado principalmente de crianças, idosos e pessoas doentes, porém os homens adultos (filhos mais velhos e marido) sáo também grandes beneficiários das atividades de care exercidas pelas mulheres, pois elas garantem a estabilidade física e emocional dos homens, uma vez que se encarregam de realizar todas as atividades relacionadas ao bem-estar deles. Importante ressaltar que grande parte dessas atividades realizadas pelas mulheres náo tem substituto no mercado e, mesmo que tivessem, não contemplariam o bem-estar, a qualidade de vida, o afeto, as relaçóes etc. Algumas podem ser substituídas apenas pelo Estado, quando este absorve as atividades ligadas ao bem-estar. 
A utilização do trabalho doméstico e de care como referencial conceitual para a análise do papel da mulher permite a visualizaçáo da disponibilidade de homens e mulheres em diferentes tarefas domésticas e, principalmente, possibilita um enfoque que não só "adiciona" as mulheres nos paradigmas tradicionais, mas que amplia a compreensão desse fenômeno, por meio da incorporação de novas perspectivas analíticas, relativamente aos diferentes trabalhos que se desenvolvem em nossa sociedade.

\section{As mulheres e as múltiplas funções da agricultura}

A principal fonte de renda declarada das famílias ${ }^{12}$ é a aposentadoria, que está presente entre a metade das famílias entrevistadas. A segunda fonte de renda mais frequente entre as famílias refere-se à produçáo de grãos, retratado nas atividades de $22 \%$ das famílias; seguida pela produçáo de leite, $17 \%$; e pelo trabalho remunerado realizado pelo marido em uma cooperativa, 11\%.

Contudo, mesmo quando a fonte de renda principal é a aposentadoria, alguma atividade agropecuária está presente como fonte secundária (realizada por 14 das 18 famílias entrevistadas). Nesses casos, a produção leiteira é a principal delas, praticada por 13 famílias. Ou seja, ainda que a renda principal seja a aposentadoria, as famílias se dedicam a trabalhar a terra. Nessas situaçóes, conforme apontam Delgado e Cardoso Júnior (2000 apud WANDERLEY, 2011), no Brasil, o recurso previdenciário acaba servindo para o investimento na agricultura, promovendo um importante impacto sobre a atividade agrícola.

Muitas famílias, apesar de terem alterado suas atividades produtivas principais, continuam mantendo o leite como fonte de renda complementar. Como na maioria dos casos a produção leiteira está vinculada a contratos de integração mantidos com as agroindústrias da regiáo, proporcionando uma renda mensal regular, ela é vista como essencial para que as famílias possam assegurar o pagamento de suas despesas mensais. A pesquisa realizada por Paulilo, De Grandi e Silva (2003) corrobora a constataçáo de que no Sul do Brasil a venda da produção de leite é essencial para assegurar uma renda mensal para suprimento das despesas fixas das famílias.

12 Apesar de minha análise recair sobre as mulheres, quando questionadas sobre a principal fonte de renda, elas sempre respondiam tendo como referência a renda familiar. 
Duas das famílias das entrevistadas orientam suas produçóes para a agroecologia. Cada agricultora produz junto com o marido uma variedade de verduras, legumes e frutas para a comercializaçáo. Uma delas também produz salames e queijos para a venda.

Das entrevistadas que trabalham com o leite (13 de 18 agricultoras), todas se dedicam ativamente ao conjunto de atividades necessárias para a produção leiteira em seu cotidiano (ordenha, pasto, limpeza etc.). Contudo, nas famílias em que o leite é a atividade principal (nove entre 13), os homens também participam dessas atividades.

Nesses casos, apesar de haver um aparente equilíbrio na divisão de tarefas realizadas, pôde-se observar, no entanto, que o homem, apesar de participar dessas tarefas cotidianas, não tem participaçáo proporcional. As diferenças principais são evidenciadas pelo desequilíbrio entre as horas dedicadas a essas atividades, assim como pela importância relativa atribuída a essas tarefas. Geralmente, cabe às mulheres o trabalho cotidiano voltado às atividades internas à propriedade, tais como: ordenhar as vacas, limpar a estrebaria, preparar a silagem, alimentar as vacas etc.; aos homens, recaem as atividades externas à propriedade, tais como: negociar a venda da produção, comprar insumos, contatar técnicos, participar em reunióes e cursos, entre outras. Quando participam das atividades internas, auxiliam as mulheres com o manejo das vacas, verificam os insumos utilizados, consertam cercas e analisam a qualidade do leite. Esse achado de pesquisa está em linha com outros estudos, como os de Magalhães (2009), Paulilo, De Grandi e Silva (2003) e De Grandi (1999).

Nas lavouras para a produçáo de grãos, as mulheres quase não participam. Segundo os relatos, essas atividades são de responsabilidade do marido e dos filhos que trabalham nas propriedades. As agricultoras afirmam participar esporadicamente do trabalho da lavoura quando são solicitadas. Em geral, essa participaçáo, quando ocorre, é realizada no período de safra. No entanto, elas alegam realizarem "trabalhos menores", que não estáo relacionados com o manejo do maquinário, aplicação de agrotóxicos e com a conduçáo de tratores.

Com relaçáo às produtoras agroecológicas, uma delas é protagonista de todo o processo produtivo, inclusive da comercializaçáo. $\mathrm{O}$ marido a auxilia quando está de folga de seu trabalho, realizado numa cooperativa. A outra produtora agroecológica relata que as tarefas diárias sáo divididas igualmente 
entre ela e o marido, porém as decisões de comercialização e a própria negociação das vendas são realizadas pelo marido.

Assim, o que pude observar foi que as mulheres participam ativamente nas atividades produtivas da agricultura, em maior ou menor escala, como são os casos da produção leiteira e do trabalho na lavoura. Isto ocorre mesmo quando o marido decide mudar o foco produtivo do estabelecimento, independentemente das escolhas ou preferências de sua esposa. Nesses casos, algumas agricultoras mencionaram não estarem satisfeitas com a decisão de cultivo de grãos, em função do elevado custo dos equipamentos e insumos, e a utilização de adubos químicos e agrotóxicos. Porém, segundo elas, como os homens haviam decidido que aquele cultivo era o de maior rentabilidade, elas acabaram por aceitar a decisão pelo fato de acreditarem que isto poderia resultar em benefícios para a sua família. Apesar de elas nem sempre concordarem com esse tipo de decisão, procuram trabalhar nessas atividades sempre que sua presença for necessária.

O que pude verificar ao analisar o espaço produtivo é que ele só é compartilhado entre homens e mulheres, ainda que de forma desigual, quando se trata de atividades em torno do trabalho. Quando o assunto recai sobre fatores relacionados à decisão, tais como a escolha da atividade produtiva principal do estabelecimento, das estratégias de comercializaçáo ou, ainda, sobre as decisóes de investimentos, o espaço compartilhado com a família torna-se um lugar de ação exclusivamente masculino.

Se o espaço de produção é eminentemente masculino, com a participação feminina, isto já não ocorre quando voltamos o nosso olhar para o espaço privado, onde são realizados os trabalhos doméstico e de care. Nesses espaços, a mulher é protagonista e os homens têm participação quase inexpressiva.

\section{Reconhecendo o papel das mulheres nas atividades domésticas e de care}

Para iniciar esta discussão, apresento um quadro com um resumo das principais atividades realizadas pelas 18 agricultoras entrevistadas nos períodos da manhá, tarde e noite, no dia anterior ao da entrevista. Essas atividades são realizadas diuturnamente por quase todas as entrevistadas, mesmo que na ocasião da entrevista algumas delas não tenham realizado algumas tarefas no 
dia anterior, podemos dizer que a tabela a seguir é representativa de um dia de trabalho das agricultoras.

Também apresento quem foi o responsável pela condução da atividade, com o intuito de verificar se as atribuiçóes eram compartilhadas com outros membros da família.

O período da manhã se inicia entre as 6 e 7 h. O horário de levantar é quase sempre o mesmo, podendo variar no fim de semana, período em que a agricultora normalmente "descansa mais uma horinha". Em todos os casos analisados, as mulheres levantam antes dos homens, geralmente uma hora antes, para irem "adiantando as coisas".

É no período da manhã que as mulheres mais trabalham. Ao despertar elas se dedicam brevemente ao cuidado pessoal e logo a seguir começam a preparar o café da manhã. Enquanto estáo preparando o café, elas, geralmente, aproveitam para ouvir as notícias no rádio e planejam o que iráo preparar para o almoço. Se necessário, já iniciam o preparo do almoço.

Após o café da manhã, elas costumam cuidar dos animais menores que, geralmente, estão próximos da casa: galinhas, animais de estimaçáo, peixes do açude, ovelhas, porcos, dentre outros. É nesse período, também, que elas aproveitam para iniciar o preparo do queijo, do pão, das massas ou dos biscoitos. Essas tarefas náo foram mencionadas como sendo rotineiras. A maioria das entrevistadas afirmou realizar o preparo do queijo, do pão e das massas, no máximo, duas vezes por semana, porém cotidianamente elas preparam, pelo menos, um desses alimentos.

Após o cuidado com os animais, as mulheres vão para estrebaria "cuidar do leite". Algumas entrevistadas, principalmente as que têm no leite a sua principal atividade produtiva, ordenham as vacas logo após o despertar, antecedido pelo chimarrão. Em seguida voltam para casa para preparar e tomar o café e retornam à estrebaria logo após o café. No início da manhã, geralmente, a lida com as vacas se resume às atividades de ordenha e alimentaçáo. $\mathrm{O}$ final da manhã e a tarde são destinados para a realização das demais atividades leiteiras. Quase todas as mulheres comentaram receber o auxílio do marido no trabalho com o leite. 


\section{Quadro I: Principais atividades realizadas, subdivididas por período e pelo principal responsável por sua execução}

\begin{tabular}{|c|c|}
\hline Período da manhã & \\
\hline Atividade principal & Com quem? \\
\hline Cuidadopessoal & Sozinha \\
\hline Preparar o café/chimarrão & Sozinha \\
\hline Cuidar dos animais (ovelhas, peixes, galinhas, vacas etc.) & Sozinha \\
\hline Preparar o queijo, o pão ou a massa & Sozinha \\
\hline Ordenha das vacas & Marido/Filhos \\
\hline Limpar a estrebaria & Sozinha \\
\hline Realizar os preparativos para o almoço & Sozinha \\
\hline Cuidar da horta & Sozinha \\
\hline Buscar as saladas e as verduras na horta & Sozinha \\
\hline Preparar almoço & Sozinha \\
\hline Almoçar & Marido/Filhos \\
\hline Limpar a cozinha e cuidar da casa & Sozinha/Filhas \\
\hline \multicolumn{2}{|l|}{ Período da tarde } \\
\hline Atividade principal & Com quem? \\
\hline Descansar (dormir cerca de uma hora) & Marido \\
\hline Trabalhar na horta & Sozinha \\
\hline Cuidar do jardim & Sozinha \\
\hline Cuidar das vacas (alimentação, limpeza etc.) & Sozinha \\
\hline Limpar a estrebaria & Sozinha \\
\hline Cortar a lenha & Sozinha \\
\hline Recolher os ovos & Sozinha \\
\hline Cuidar da casa (geralmente cuidar da roupa) & Sozinha \\
\hline Receber amigos/visitar vizinhos ou parentes & Marido/Filhos \\
\hline \multicolumn{2}{|l|}{ Período da noite } \\
\hline Atividade principal & Com quem? \\
\hline Tomar chimarrão & Marido \\
\hline Preparar o jantar & Sozinha \\
\hline Jantar & Marido/Filhos \\
\hline Assistir televisão & Marido/Filhos \\
\hline Lavar a louça & Sozinha/Filhas \\
\hline Preparar a comida para o dia seguinte (escolher o feijão, descongelar a carne etc.) & Sozinha \\
\hline Cuidado pessoal & Sozinha \\
\hline Dormir & Marido \\
\hline
\end{tabular}

Fonte: Elaborado pela autora a partir de dados empíricos coletados. 
Além da ordenha, outro serviço realizado no período da manhã é a limpeza da estrebaria. Nesse caso, se na ordenha, alimentaçáo e no manejo das vacas elas relataram receber a contribuição do marido, a limpeza da estrebaria é realizada somente por elas. Após a lida com as vacas, iniciam-se os preparativos para o almoço, a limpeza da casa e o cuidado com a horta. Quando os homens voltam da roça, o almoço é servido. O cuidado com a horta e com os pomares ocorre em meio a outras tarefas: na ida ou na volta da estrebaria, enquanto o almoço é preparado ou a casa é limpa.

Os relatos a seguir exemplificam a rotina matinal das agricultoras:

[...] não, o banho é depois do leite (risos). Depois, dai eu ponhei o leite esquentar, que daí eu faço o queijo tudo os dia. Daí fui pra fora, tratei minhas galinha. Que dai as galinha também é separada, eu tenho duas turma e a filha o resto. (risos). (Entrevistada 3).

Eu tirei leite, depois... espera que eu vou pensá no que eu fiz ontem. Eu molhei as verdura... eu preparei um cantero pra plantá tomate, adubei o pedacinho né... depois eu limpei aqui [a casa], limpei a área aqui. Lá com o leite era 8h, 8h30min, dai entrei, dai fui levá as vaca também, levá as vaca no pasto...dai, na hora que molho as flor, as verdura era 9h30min mais ou menos, é a rotina do dia. (Entrevistada 14).

As agricultoras aposentadas que náo se ocupam com a lida do leite, dedicam-se ao cuidado com a casa, com as atividades da horta e dos pomares.

No caso das agricultoras que têm filhas residindo na propriedade (cinco das 18 entrevistadas), as filhas auxiliam no trabalho doméstico. Contudo, a prioridade das filhas sempre está voltada para as atividades escolares. Elas contribuem com o cuidado e limpeza da casa, quando não estão na escola ou quando já finalizaram as tarefas escolares. Em nenhum caso as filhas auxiliam as mães com as atividades do leite ou agrícolas.

O período da manhã se encerra em torno das $12 \mathrm{~h} 30 \mathrm{~min}$, logo após o almoço; e o período da tarde se inicia entre $13 \mathrm{~h}$ e $13 \mathrm{~h} 30 \mathrm{~min}$, após o descanso. A rotina da tarde se assemelha à da manhã, com exceção das lidas com a casa, que raramente ocorre, pois as mulheres costumam deixar tudo preparado já no início da manhã. À tarde, quando ocorre alguma atividade doméstica, ela, em geral, está relacionada com o cuidado com as roupas.

No período da tarde, elas retornam à estrebaria para ordenhar as vacas, limpar o local, levar e buscar as vacas no pasto, dentre outros serviços relacionados. Também voltam a trabalhar na horta, cuidar dos arredores da casa, dos 
pomares, dos jardins e alguma pequena plantação na lavoura. As mulheres também aproveitam para realizar alguma atividade que não conseguiram finalizar na manhã, tal como recolher ovos, tratar os animais, recolher a lenha, finalizar o queijo ou pão. Nesse período, as tarefas são, majoritariamente, externas à casa. $\mathrm{O}$ trecho da entrevista a seguir ilustra a rotina deste período do dia:

É, isso. Daí voltei de fazer o piquete pras vaca, fui semear cenoura na horta. Que nós temo o jornal [com as explicações do que plantar]. Dai ontem era dia de semear a raiz, fui me plantar a cenoura. Dai depois quando eu plantei a cenoura, subi lá na roça. Daí a máquina ia limpar o pedaço lá aonde que tinha as batata e as mandioca. Daí arranquei as batata, arranquei as mandioca. E dai, depois, quando acabei de arrancar as batata e as mandioca, vim de volta. Dai comecei, tirei leite de novo, tratei os bicho. (Entrevistada 6).

O período da noite se inicia próximo das $18 \mathrm{~h} 30 \mathrm{~min}$ no inverno, ocasiáo em que realizei a pesquisa de campo. Esse é um período do dia menos intenso em relação ao trabalho produtivo e está voltado às tarefas internas da casa. "Logo após vir pra dentro" elas costumam tomar chimarrão com o companheiro e filhos, ocasiáo que funciona também como "momento de prosa", para falar sobre o dia, contar como estão os animais, as plantaçôes, os vizinhos etc.

Após o chimarrão, elas já começam a realizar os preparativos para o jantar. Todas comentaram preparar algo rápido à noite. Em geral, esquentam a comida do almoço ou comem polenta e páo com café e leite.

Após o jantar, as mulheres limpam a cozinha, realizando ainda algumas atividades adicionais relacionadas ao almoço do dia seguinte: escolhem o feijão, separam a carne ou fazem a polenta. Concomitante a essas tarefas, elas costumam assistir televisão com o marido e os filhos. Eles sentados no sofá e elas trabalhando. Quando todas as atividades da casa foram enfim finalizadas, as agricultoras se dedicam ao cuidado pessoal, indo dormir entre $22 \mathrm{~h} 30 \mathrm{~min}$ e $23 \mathrm{~h}$.

Como sugere a descrição das atividades das agricultoras, todas elas se dedicam integralmente aos serviços do estabelecimento, tanto àqueles relacionados às atividades produtivas quanto às atividades domésticas e de care, o que corrobora a tese da dupla jornada de trabalho feminina ${ }^{13}$. Contudo, o

13 Segundo Boris (2014), "[...] uma extensa literatura nas ciências sociais mostra que [...] as mulheres alocam muito mais horas do que os homens nas atividades de cuidados pessoais e de reprodução social, de modo que, [...], elas trabalham tanto quanto se tivessem um outro emprego, em tempo parcial". 
trabalho doméstico é o que mais ocupa o tempo das mulheres. Nota-se, nas suas falas, que, principalmente no período da manhã e da noite, elas ficam mais envolvidas com as tarefas da casa. Assim, podemos sugerir que, o que sobrecarrega a mulher náo são as tarefas produtivas ou domésticas e de care separadamente, mas sim as tarefas simultâneas (PAULILO, 2003).

Esses dados evidenciam a afirmação de Faria (2009), ao considerar as agricultoras como um "recurso inesgotável", responsável pelo cuidado com a casa, com os membros da família, com a produção para autoconsumo, com o trabalho produtivo e com as demais atividades que envolvam o estabelecimento agrícola e suas famílias. Os homens se mostraram mais participativos apenas quando as suas esposas estão fora do estabelecimento. Todavia, a participação deles nas tarefas domésticas está mais voltada para a sua própria manutençáo biológica, como no caso do preparo dos alimentos. Em nenhum caso foi observado ou mencionado que o marido se encarregava de cuidar da casa, dos filhos, dos quintais, das hortas e dos pomares na ausência eventual da esposa.

Em algumas situações, não muito frequentes, foi possível verificar o "modelo de delegação", expressão cunhada por Hirata e Kergoat (2007) para se referir à situação na qual uma mulher atribui a outra a realização do trabalho doméstico, por meio da ajuda de filhas, sogras e vizinhas. Contudo, nenhuma das agricultoras contava com empregada doméstica remunerada, ou seja, elas não recorriam ao "modelo de delegaçáo" por meio de pagamento.

Em todas as atividades cotidianas, o care está presente uma vez que os trabalhos doméstico e de care geralmente se sobrepóem, pois o care é considerado como um componente do trabalho reprodutivo, que náo equivale ao trabalho doméstico, mas é, geralmente, executado junto com as atividades domésticas.

O trabalho cotidiano das agricultoras está voltado, quase sempre, para o cuidado de outrem em prol da reproduçáo biológica e social, manutenção e bem-estar das famílias. Ademais, além das próprias atividades cotidianas, algumas entrevistadas se encarregavam de realizar cuidados com membros doentes e idosos da família.

Dentre as minhas entrevistadas, sete convivem com um parente enfermo e, nessas situaçóes, cabe a elas o cuidado de "existência pessoal" ${ }^{14}$ desses

14 Citado por Boris (20/4) 
indivíduos. Ou seja, a dedicação a essas pessoas, além dos cuidados de manutenção com a casa, envolve, também, dar banho, alimentar, acompanhar, transportar, dar atençáo e afeto ${ }^{15}$.

Com relação aos filhos, as entrevistadas não têm filhos pequenos, a filha mais nova tem 10 anos. Por esse motivo, além do care, presente nas atividades cotidianas, elas não necessitam dedicar tempo extra aos "cuidados necessários" dos filhos. Todavia, o care sempre está presente quando se trata do relacionamento com os filhos, mesmo que estes já não convivam diariamente com as agricultoras. Nesses casos, sempre existe uma responsabilidade moral de care - conforme a expressão usada por Tronto (1993), taking care of - para com os seus filhos.

Se as mulheres são responsáveis pelas atividades de care dos filhos, do marido, dos idosos e doentes. Ninguém se encarrega dos cuidados com elas. Diversos relatos evidenciaram que as mulheres entrevistadas sofrem de problemas de saúde, tais como dores nas costas, problemas no joelho, artrite e tendinite. Muitas destas doenças estão diretamente relacionadas à lida cotidiana da agricultura. Porém, elas mesmas se encarregam de seus cuidados, realizando tratamento médico ou evitando certos movimentos que lhes prejudiquem a saúde. Tudo isso, sem deixar de dar conta de seu serviço para não prejudicar os demais familiares.

\section{Considerações finais}

No estudo de caso analisado neste artigo, pudemos verificar que as agricultoras têm papel fundamental no que concerne à manutenção e reprodução social da agricultura familiar, uma vez que as suas atividades cotidianas estão relacionadas integralmente às suas famílias e a seus estabelecimentos agrícolas. No âmbito das atividades geradoras de renda, importantes para a manutenção financeira da família, as agricultoras atuam diuturnamente em quase todas as tarefas da unidade produtiva familiar. Além disso, são responsáveis pelos trabalhos domésticos e de care, que permitem a manutenção da vida e bem-estar das famílias.

15 Tronto (2007, p. 29I) chama este tipo de trabalho de "cuidado necessário". 
No espaço produtivo, ainda que observado uma desigualdade de gênero quanto à divisão do trabalho, as mulheres tomam a frente ou participam de todas as atividades que lhes sáo atribuídas: seja na atividade leiteira, na qual elas são responsáveis por quase todo processo produtivo; seja na produção de grãos, em que cada uma delas afirma auxiliar o marido apenas quando é solicitada.

Já os trabalhos domésticos e de care recaem integralmente e exclusivamente sobre elas, pois as mulheres são as responsáveis pelo cuidado, pela manutenção da força de trabalho, pelo bem-estar e reprodução social das famílias. Além desse recorrente trabalho cotidiano, no qual o care, muitas vezes, se confunde com o trabalho doméstico, elas também são responsáveis pelo "cuidado necessário" de parentes idosos e enfermos.

A função da reprodução socioeconômica, quando analisada à luz da multifuncionalidade agrícola, possibilita que a sociedade e as próprias famílias rurais reconheçam o papel central que as agricultoras exercem, pois as atividades realizadas pelas mulheres são retiradas do seu ocultamento. Contudo, se o reconhecimento é importante, ele não é suficiente. Existem barreiras significativas que as mulheres ainda têm de enfrentar. Uma delas refere-se à divisão das tarefas com os companheiros e os filhos no âmbito dos trabalhos doméstico e de care. A outra se constitui na presença ainda precária do Estado em investimentos em infraestruturas e na elaboração de políticas públicas adequadas a esse segmento específico.

À guisa de conclusão, este estudo teve como intenção principal contribuir para o processo de visibilizaçáo das atividades exercidas pelas mulheres rurais. Não obstante a histórica falta de reconhecimento acerca do papel das mulheres na agricultura, suas atuaçóes como sujeitos políticos têm permitido afirmar suas identidades e articular os seus interesses.

Acredito que a abertura de espaços políticos, como os realizados pelos movimentos sociais de mulheres, e estudos de gênero que auxiliem a compreender o papel da mulher no meio rural, a partir de enfoques analíticos que náo priorizem somente a função econômica da agricultura, poderá subsidiar a elaboraçáo de políticas públicas voltadas para a realidade das mulheres do campo, principalmente no que se refere ao trabalho doméstico e de care que, como mencionado anteriormente, sobrecarregam as mulheres do campo. 
$\mathrm{O}$ ato de redirecionar o nosso olhar para o meio rural, a partir da lente analítica da multifuncionalidade da agricultura, possibilita enxergá-lo através de novas perspectivas, que consideram a manutençáo e a reproduçáo social da agricultura familiar como eixos fundamentais para a produção agrícola, para a preservação do meio ambiente, para o fortalecimento de redes sociais e como condição de cidadania. Nesse movimento, encontramos um caminho para o desvelamento de relaçóes de desigualdade de gênero, mantidas historicamente na nossa sociedade, assim como, localizamos novas possibilidades de reinterpretação e ação para as mulheres no meio rural.

\section{Referências}

ABRAMOVAY, R. O futuro das regióes rurais. Porto Alegre: Ed. UFRGS, 2009.

BONI, V. De agricultoras a camponesas: o Movimento de Mulheres Camponesas em Santa Catarina e suas práticas. 2012. 253 f. Tese (Doutorado em Sociologia Política) Programa de Pós-Graduação em Sociologia Política, Universidade Federal de Santa Catarina, Florianópolis, 2012.

BORDERÍAS, C.; CARRASCO, C.; TORNS, T. Introducción: el trabajo de cuidados: antecedentes históricosy debates actuales. In: . (Ed.). El trabajo de

cuidados, historia, teoría y políticas. Madrid: Catarata, 2011. p. 13-96.

BORIS, E. Produção e Reprodução, casa e trabalho. Revista Tempo Social, São Paulo, v. 26, n. 1, p. 101-121, 2014.

BOURDIEU, P. Razóes práticas: sobre a teoria da ação. Campinas: Papirus, 1996.

Las estrategias de reproducción social y modos de dominación. Colección Pedagógica Universitária, México, n. 37/38, p. 41-67, 2002.

BRUMER, A. Gênero e agricultura: a situação da mulher na agricultura do Rio Grande do Sul. Revistas de Estudos Feministas, Florianópolis, v. 2, n. 1, p. 205-227, jan./abr. 2004.

BRUMER, A; DOS ANJOS, G. Gênero e reprodução social na agricultura familiar. Revista Nera, Presidente Prudente, v. 11, n. 12, p. 6-17, 2008.

CARNEIRO, M. J. "Rural” como categoria de pensamento. Rurais, v. 2, n. 1, p. 9-38, mar. 2008 .

.; MALUF, R. Introdução. In: .(Org.) Para Além da Produção:

Multifuncionalidade e Agricultura Familiar.Rio de Janeiro: MAUAD, 2003. p. 17-26. 
CAZELLA, A.; BONNAL, P.; MALUF, R. Multifuncionalidade da agricultura familiar no Brasil e o enfoque da pesquisa. In: Agricultura Familiar: multifuncionalidade e desenvolvimento territorial no Brasil. Rio de Janeiro: MAUAD, 2009. p. 47-70.

DEERE, C.; LEÓN, M. O empoderamento da mulher. Porto Alegre: Ed. da UFRGS, 2002. DE GRANDI, A. Relaçóes de gênero nas famílias agricultoras associadas a miniusinas de leite no estado de Santa Catarina1999. 99 f. Dissertação (Mestrado em Sociologia Política) - Programa de Pós-Graduação emSociologia Política, Universidade Federal de Santa Catarina, Florianópolis, 1999.

FARIA, N. Economia feminista e agenda de lutas das mulheres no meio rural. In: BUTTO, A. (Org.). Estatísticas Rurais e a Economia Feminista: um olhar sobre o trabalho das mulheres. Brasília: MDA, 2009. p. 11-28.

GAVIOLI, F; COSTA, M. B. As múltiplas funçóes da agricultura familiar: um estudo no assentamento Monte Alegre, região de Araraquara (SP). Revista Economia Sociologia Rural, Brasília, v. 49, n. 2, p. 449-472, abr./jun. 2011.

GELINSKI, C.; PEREIRA, R. Mulher e Trabalho Não Remunerado. Mulher e Trabalho, v. 5 , p. 79-87, 2005.

GUIMARÁES, N.; HIRATA, H.; SUGITA, K. Cuidado e Cuidadoras: O trabalho de care no Brasil, França e Japáo. Revista Sociologia \& Antropologia, Rio de Janeiro, v. 1, n. 1, p. 151-180, 2011.

HIRATA, H. Teorias e Práticas do Care: Estado Sucinto da Arte, Dados de Pesquisa e Pontos de Debate. In: FARIA, N.; MORENO, R. (Org.). Cuidado, Trabalho e Autonomia das Mulheres. São Paulo: Editora Sempreviva, 2010. p. 42-56.

.; KERGOAT, D. Novas Configuraçóes da Configurações da Divisão Sexual do Trabalho. Cadernos de Pesquisa, Rio de Janeiro, v. 37, n. 132, p. 595-609, set./dez. 2007.

HUYLEBROECK, Guido; VANDERMEULEN, Valerie; METTEPENNIGEN, Evy; VERSPECHT, ANN. Multifunctionality of Agriculture: A Reviewof Definitions, Evidenceand Instruments. Living Rev. Landscape Res., v.1, n. 3, 2007. MAGALHÁES, R. A "masculinizaçáo" da produção de leite. Revista de Economia e Sociologia Rural, Piracicaba, v. 47 , n. 1 , p. $275-300,2009$.

MURDOCH, J. Networking rurality: the emergente complexity in the countryside. In: CLOKE, P. et al. (Org.). Handbook of Rural Studies. London: Sage Publications Ltd, 2006. p. $171-184$. 
NEVES, D; MEDEIROS, L. (Org.). Mulheres camponesas: trabalho produtivo e engajamentos políticos. Niterói: Alternativa, 2013.

PAUliLO, M. I. O peso do trabalho leve. Revista Ciência Hoje, Rio de Janeiro, v. 5, n.28, p. 64-70, 1987.

Movimento de mulheres agricultoras: terra e matrimônio. In. PAULILO, M. I.; SCHMIDT, W. (Org.). Agricultura e espaço Rural em Santa Catarina. Florianópolis: Editora da UFSC, 2003. p. 183-210.

.; DE GRANDI, A.; SILVA, M. M. Mulher e atividade leiteira: a dupla face da exclusão. In: PAULILO, M. I.; SCHMIDT, W. (Org.). Agricultura e espaço Rural em Santa Catarina. Florianópolis: Editora da UFSC, 2003. p. 15-38

SABOURIN, E. Implicaçôes teóricas e epistemológicas do reconhecimento da noção de multifuncionalidade da agricultura. Revista Estudos Sociedade e Agricultura, Rio de Janeiro, v. 13, n. 2, p. 161-189, 2005.

SCOTT, J. Gênero: uma categoria útil de análise histórica. Educaçáo \& Realidade. Porto Alegre, v. 20, n. 2, p. 71-99,1995. SORJ, B. Os cuidados com a família e as desigualdades de gênero e classe. In: COSTA, A.; ÁVILA, M. B. de M.; SILVA, R.; SOARES, V., FERREIRA, V. (Org.). Divisão do Trabalho, Estado e Crise do Capitalismo. Recife: Ediçóes SOS Corpo, 2010. p. 57-66.

TRONTO, J. Un monde vulnérable. Pour une politique du care.Textes à l'appui/philosophie pratique.Paris: La Découverte, 1993. . Assistência Democrática e Democracias Assistenciais. Revista Sociedade e Estado, Brasília, v. 22, n. 2, p. 285-308, 2007.

WANDERLEY, M. N. Um saber necessário. Os estudos rurais no Brasil. Editora Unicamp, 2011.

A emergência de uma nova ruralidade nas sociedades modernas avançadas - o "rural" como espaço singular e ator coletivo. Revista Estudos Sociedade e Agricultura, Rio de Janeiro, v. 15, p. 87-145, out. 2000.

Prefácio. In: CARnEIRO, M. J.; MALUF, R. S. (Org.) Para Além da Produção: Multifuncionalidade e Agricultura Familiar. Rio de Janeiro: MAUAD, 2003a. p. 9-16.

- Agricultura familiar e campesinato: rupturas e continuidade. Revista Estudos Sociedade e Agricultura, Rio de Janeiro, v. 21, p. 42-61, 2003b. 
WEINSTOCK, A. M. Aportes del feminismo a la lucha socioambiental. Revista de Estudos Feministas, Florianópolis, v. 22, n. 2, p. 647-655, maio/ago. 2014.

Recebido em: 15/07/2016. Aceito em: 03/10/2016.

\section{From Invisibility to Recognition: rural women, productive activities, household activities and care}

\section{Abstract}

This article aims to discuss the situation of invisibility and lack of recognition of women in rural areas of Southern Brazil, throughout the reflection of the possibilities for overcoming their condition. For this purpose, it was suggested the analytical perspective of agricultural multifunctionality for the analysis of the activities carried out by rural women, since this approach aims to go beyond purely production-oriented approaches and aims to highlight the non-productive roles of agriculture. In the empirical research had been identified the various and diverse activities that set up the productive work, domestic and care work of a group of 18 farmers members of the Movement of Peasant Women (MMC) and residents in Quilombo, municipality in Western Santa Catarina, in Southern Brazil. The research turned out that women farmers play a fundamental role regard the maintenance and social reproduction of family farming, since their daily activities are integrally related to their families and their farms. In this perspective, the perspective of multifunctionality operates as a powerful tool that allows visualization of the role of women in rural areas.

Keywords: Rural Women. Multifunctionality of Agriculture. Gender. Rural Sociology. 